\title{
The relationship between Nrf2/Keap1 system and endoplasmic reticulum stress and inflammatory markers in peripheral blood mononuclear cells of type 2 diabetic subjects
}

\section{ABSTRACT}

Background. Oxidative stress, endoplasmic reticulum stress (ER stress), and inflammation are the main leading factors in the pathogenesis of type 2 diabetes. Nuclear factor erythroid 2-related factor 2 / Kelch-like $\mathrm{ECH}$-associated protein 1 (Nrf2/Keap1) is the chief regulator of the antioxidant defense system that protects the cells against reactive oxygen species (ROS). ER stress and inflammatory pathways are involved in the suppression or the activation of the Nrf2/Keap1 system. In this study, we aimed to explore the possible relationships of the main factors contributing to oxidative stress, endoplasmic reticulum stress, and inflammation in peripheral blood mononuclear cells (PBMCs) of diabetic patients.

Methods. Levels of biological parameters, oxidative stress markers as well as the gene transcription of Nrf2, Keap1, p22 ${ }^{\text {phox }}$, Chop1, Grp78, IL-6, and TNF- $\alpha$ were analyzed in the PBMCs of 32 type 2 diabetic and 31 non-diabetic subjects. The correlation analysis was per-

Address for correspondence:

Reza Meshkani,

Department of Clinical Biochemistry,

Faculty of Medicine,

Tehran University of Medical Sciences,

Tehran, Iran

e-mail: rmeshkani@tums.ac.ir

Clinical Diabetology 2021, 10 10; 5: 394-402

DOI: 10.5603/DK.a2021.0032

Received: 20.07.2020

Accepted: 27.12 .2020 formed for the markers of oxidative stress with selected ER stress-related genes and pro-inflammatory cytokines. Results. Fasting blood sugar $(P<0.0001), \mathrm{HbA}_{1 \mathrm{c}}$ $(P<0.0001)$, serum triglycerides $(P=0.024)$, insulin $(P=0.003)$, and HOMA2-IR $(P=0.016)$ were significantly higher in diabetic patients compared with nondiabetic subjects. Levels of malondialdehyde (MDA) and carbonyl content were higher in the diabetes group. Conversely, total thiol content, and ferric reduction of plasma was higher in the healthy group. The mRNA levels of Nrf2 were negatively correlated with Keap1 and IL-6 gene expression. We observed a significant positive correlation between mRNA levels of Chop1, Grp78, and Nrf2 transcription levels.

Conclusion. The data of the present study suggest that the impaired function of the Nrf2/Keap1 system is associated with pathological factors such as ER stress and inflammation. (Clin Diabetol 2021; 10; 5: 394-402)

Key words: reactive oxygen species, type 2 diabetes, oxidative stress, endoplasmic reticulum stress, inflammation

\section{Introduction}

Type 2 diabetes mellitus (T2DM) is a metabolic disorder considered to be pandemic and its prevalence is rising drastically in both developed and developing countries. According to the estimates of the American Diabetes Association, approximately 451 million people 
were afflicted with diabetes globally in 2017 and it is expected to rise to 693 million in 2045 [1].

It has been shown that oxidative stress has a great number of adversary effects on glucose homeostasis. Oxidative stress stimulates stress-responsive pathways and it is associated with the development of insulin resistance, pancreatic $\beta$-cell dysfunction, mitochondrial dysfunction, and atherosclerosis in people afflicted with diabetes [2-5]. Oxidative stress is described as a condition in which the equilibrium between production and elimination of reactive oxygen species (ROS) is disturbed. Under physiological conditions, antioxidant constituents are capable to sustain the levels of ROS in normal ranges but in some pathological conditions such as T2DM and obesity, the capacity of this protective system is impaired due to excess amount of ROS [6]. Cells are already prepared for these possible injuries by equipping themselves with antioxidant defense mechanisms including phase II detoxifying and antioxidant enzymes to combat ROS $[7,8]$. The transcription factor nuclear factor erythroid 2-related factor 2 (Nrf2) with its negative regulator Kelch-like $\mathrm{ECH}$-associated protein 1 (Keap1) plays a critical role in maintaining intracellular redox homeostasis $[9,10]$. The mechanisms by which oxidative stressors induce disassociation of Nrf2 from Keap1 are explained elsewhere [11, 12]. It has been stated that binding of Nrf2 to the antioxidant responsive element (ARE) in the nucleus, mediates maintenance of redox status and antioxidant activity by inducing several antioxidant enzymes including peroxiredoxin (PRX) families, thioredoxin (TRX), glutathione S-transferases (GST), cytosolic copper-zinc superoxide dismutase (CuZnSOD), mitochondrial manganese superoxide dismutase (MnSOD) glutathione reductase (GR), and heme oxygenase-1 (HO-1) [7].

Endoplasmic reticulum stress is involved in the pathogenesis of T2DM. The ER is responsible for folding of proteins in maturation steps of a protein [13]. There are specific sensors in ER trans-membrane which detect the unfolded or misfolded proteins. These sensors are protein kinase-like ER kinase (PERK), inositol requiring kinase 1 (IRE1), and the transcriptional factor activating transcription factor 6 (ATF6) which are sustained dormant by glucose-regulated protein $78 \mathrm{kDa}$ (GRP78/BiP). Accumulation of unfolded and misfolded proteins in the ER is called ER stress. When ER stress occurs, unfolded protein response (UPR) attempts to overcome the crisis through disassociation of GRP78 from ER trans-membrane sensors. In the case of UPR failure, the cell initiates apoptosis by activation of CCAAT/enhancer-binding protein homologous protein (CHOP) known as death factor [14, 15].
Chronic hyperglycemia as a stressor could trigger inflammatory responses in the tissues [16]. Inflammation is the first line in combating pathogens to return the damaged cell or tissue to its normal condition [17]. The initiation of inflammatory responses stimulates the production of multiple pro-inflammatory cytokines and chemokines such as tumor necrosis factor $\alpha$ (TNF- $\alpha$ ) and interleukin-6 (IL-6). It has been shown that TNF- $\alpha$ and IL- 6 alter the $\beta$ cells function and play a fundamental role in the development of insulin resistance $[16,18]$.

As mentioned earlier, oxidative stress, ER stress, and inflammation play key roles in the onset and development of diabetes [7, 19]. However, less information are available about the interconnections of oxidative stress, ER stress, and inflammation in clinical settings. Therefore, in this study we aimed to investigate the interconnections of the mentioned factors in peripheral blood mononuclear cells (PBMCs) of diabetic and non-diabetic individuals. Understanding the exact mechanisms by which mentioned factors take part in the progression of T2DM will expand the opportunities in the probable future treatment of the disease.

\section{Materials and methods}

\section{Subject recruitment}

This study was approved by the Ethics Committee of Tehran University of Medical Sciences and all participants gave written informed consent before the blood collection. Two groups of subjects were enrolled in the study: 31 non-diabetic control subjects and 32 type 2 diabetic patients. Diabetes was defined as fasting glucose more than $126 \mathrm{mg} / \mathrm{dl}$ or use of hypoglycemic medication. Major requirements for non-diabetic control subjects were: the absence of diabetes and inflammatory diseases, and diabetic patients were enrolled in the study based on their previous records of diabetes. Exclusion criteria for diabetic patients were: diabetes type 1, insulin treatement, renal failure, and cancer. Fasting blood samples were collected in heparinized tubes.

\section{Physical measurements}

Standard methods were applied for the measurement of height, weight, blood pressure, waist, and hip circumferences. Body mass index (BMI) was calculated by using the ratio of weight to the square of height in meters $\left(\mathrm{kg} / \mathrm{m}^{2}\right)$. Insulin resistance was estimated by Homeostatic Model Assessment of Insulin resistance (HOMA-IR), using the HOMA2 calculator software. HOMA2 calculator was downloaded from University of Oxford (www.dtu.ox.ac.uk). 


\section{Biochemical parameters}

Venous blood samples were obtained from all the participants after an overnight fast, and the fresh blood was centrifuged at $3000 \times \mathrm{g}$ for 5 minutes, then plasma was held in $-80^{\circ} \mathrm{C}$ for storage until assayed. Biochemical analyses were done on BIOLIS 24i Premium Autoanalyser (Tokyo Boeki Machinery Ltd., Japan). The biochemical tests included fasting blood sugar (FBS), total cholesterol, LDL-C, HDL-C, triglycerides, urea, uric acid, creatinine, total protein, serum glutamic oxaloacetic transaminase (SGOT), serum glutamic pyruvic transaminase (SGPT), and high-sensitivity C-reactive protein (hsCRP). $\mathrm{HbA}_{1 c}$ was measured with HPLC method by the Tosoh G8 instrument (South San Francisco, CA), and insulin was measured by Insulin AccuBind ELISA Kit (Monobind Inc, California, USA). Relative mRNA expression of multiple genes associated with ER stress, oxidative stress, and inflammation was studied in the PBMCs of both groups. The obtained data from all the participants included age, sex, duration of diabetes, family history of diabetes and cancer, consumption of medications and alcohol, cigarette smoking, and history of myocardial infarction.

\section{Assessment of oxidative stress biomarkers in serum}

Malondialdehyde (MDA) as a product of lipid peroxidation was measured. The Thiobarbituric acid reactive substance (TBARS) method was used for the measurement of MDA, where MDA reacts with TBA and gives a pink-colored species that absorbs at $532 \mathrm{~nm}$, as described elsewhere [20]. The ferric reducing antioxidant power (FRAP) assay was performed to determine the total antioxidant capacity (TAC) of plasma. This method is based on the reduction of ferric tripyridyltriazine (Fe III-TPTZ) complex to ferrous (Fe-II) ion formation by antioxidants at low $\mathrm{PH}$, and this coloration gives rise to the creation of a blue color, which absorbs at $593 \mathrm{~nm}$ [21]. Also, protein carbonyl content as a marker of oxidative damage was assessed by 2, 4-dinitrophenylhydrazine (DNPH) assay. In this method, protein carbonyl groups react with reagent DNPH and lead to the formation of 2,4-dinitrophenyl (DNP) hydrazone product, which absorbs at $370 \mathrm{~nm}$ [22]. Total thiol content was assessed by the spectrophotometric method using 5,5'-dithiobis-(2nitrobenzoic) acid (DTNB) known as Ellman's reagent. Thiol groups react with DTNB and generate 5-thio2-nitrobenzoic acid (TNB), which absorbs at $412 \mathrm{~nm}$ [23].

\section{PBMC isolation}

Whole blood collected in the heparinized tubes and was gently layered on the Ficoll-Hypaque density gradient and centrifuged at $800 \mathrm{~g}$ for 40 minutes. PBMCs
Table 1. Primer sequence of selected genes

\begin{tabular}{cl}
\hline Gene & \multicolumn{1}{c}{ Sequence } \\
\hline Nrf-2 & \\
Forward & TACTCCCAGGTTGCCCACA \\
Reverse & CATCTACAAACGGGAATGTCTGC \\
Keap-1 & \\
Forward & TCTTACGCCCTTGCAGGT \\
Reverse & CTACCGTCCCCACCCAC \\
p22 & \\
Forward & CCCAGTGGTACTTTGGTG \\
Reverse & GCGGTCATGTACTTCTGTC \\
Grp-78 & \\
Forward & CTGCCATGGTTCTCACTAAAATG \\
Reverse & TTAGGCCAGCAATAGTTCCAG \\
Chop-1 & \\
Forward & GTACCTATGTTTCACCTCCTGG \\
Reverse & TGGAATCTGGAGAGTGAGGG \\
TNF- $\alpha$ & \\
Forward & CCCAGGCAGTCAGATCAT \\
Reverse & TCAGCTCCACGCCATT \\
IL-6 & \\
Forward & GACAGCCACTCACCTCTT \\
Forward & TGTTTTCTGCCAGTGCC \\
Reverse & AGAGCTACGAGCTGCCTGAC \\
\hline & \\
\hline
\end{tabular}

were isolated and washed with PBS for three times and stored in -80 freezer prior to the RNA extraction.

\section{RNA isolation and real-time PCR}

The total RNA was extracted from PBMCs by using the Gene-All Hybrid-R RNA purification kit and following the manufacturer's instructions (Gene-All Biotechnology Co., Seoul, South Korea). Reverse-transcription of RNA into CDNA was performed by using a Revert Aid RT Reverse Transcription Kit (Thermo Fisher, USA). The quantity of isolated RNA was measured by Nanodrop and the formaldehyde-agarose gel electrophoresis was applied for assessing the quality of RNA. Quantitative real-time $P C R$ via the $A B I$ machine was conducted by taking advantage of SYBR Green RealQ Plus $2 \times$ Master Mix Green (Ampliqon). The duplicate values for each sample were used to validate the changes in the gene expression. The relative expression levels of mRNA encoding Nrf2, Keap1, Chop1, p22 $2^{\text {phox }}$, Grp78, IL-6, and TNF- $\alpha$ were determined by using $2^{\wedge}-\Delta \mathrm{Ct}$ method. $B$-actin expression was used to normalize the differences in each sample. The NCBI primer Blast was used for designing of primer sequences. The forward and reverse sequences of primers are presented in Table 1. 
Table 2. Clinical and biochemical characteristics of the study groups

\begin{tabular}{|c|c|c|c|}
\hline Parameter & Non-diabetic subjects $(n=31)$ & Diabetic patients $(n=32)$ & P-value \\
\hline Age [years] & $50.23 \pm 6.63$ & $56.81 \pm 6.05$ & $<0.0001$ \\
\hline $\operatorname{Sex}[M / F]$ & $16 / 15$ & $18 / 14$ & 0.71 \\
\hline $\mathrm{SBP}[\mathrm{mm} \mathrm{Hg}]$ & $120.93 \pm 11.82$ & $131.16 \pm 17.43$ & 0.009 \\
\hline $\mathrm{DBP}[\mathrm{mm} \mathrm{Hg}]$ & $80.29 \pm 9.40$ & $81.03 \pm 11.36$ & 0.779 \\
\hline Weight [kg] & $73.00(70.00,80.50)$ & $77.50(73.00,95.25)$ & 0.037 \\
\hline BMI $\left[\mathrm{kg} / \mathrm{m}^{2}\right]$ & $26.20(24.91,29.75)$ & $26.68(25.63,33.18)$ & 0.274 \\
\hline Waist [cm] & $97.22 \pm 9.47$ & $102.53 \pm 11.63$ & 0.052 \\
\hline Hip [cm] & $105.16 \pm 6.38$ & $109.56 \pm 10.54$ & 0.05 \\
\hline WHR & $0.92 \pm 0.07$ & $0.93 \pm 0.06$ & 0.301 \\
\hline $\mathrm{FBS}[\mathrm{mg} / \mathrm{dL}]$ & $93.29 \pm 7.6$ & $141.22 \pm 42.36$ & $<0.0001$ \\
\hline $\mathrm{HbA}_{1 \mathrm{c}}[\%]$ & $5.8(5.5,6)$ & $7.55(6.62,8.87)$ & $<0.0001$ \\
\hline HOMA2-IR & $1.33 \pm 1.1$ & $1.71 \pm 0.92$ & 0.016 \\
\hline Total Chol [mg/dL] & $184.77 \pm 39.15$ & $149 \pm 30.6$ & $<0.0001$ \\
\hline TG [mg/dL] & $107.11 \pm 39$ & $137.74 \pm 59.19$ & 0.024 \\
\hline $\mathrm{HDL}-\mathrm{c}[\mathrm{mg} / \mathrm{dL}]$ & $47.23 \pm 12.63$ & $44.13 \pm 12.18$ & 0.325 \\
\hline LDL-c [mg/dL] & $119.72 \pm 28.95$ & $89.44 \pm 26.40$ & $<0.0001$ \\
\hline Insulin $[\mu \mathrm{U} / \mathrm{mL}]$ & $9.36 \pm 3.51$ & $13.94 \pm 7.32$ & 0.003 \\
\hline Urea $[\mathrm{mg} / \mathrm{dL}]$ & $28.78 \pm 9.45$ & $31.26 \pm 6.95$ & 0.244 \\
\hline Creatinine $[\mathrm{mg} / \mathrm{dL}]$ & $0.84 \pm 0.20$ & $0.76 \pm 0.17$ & 0.105 \\
\hline Uric Acid[mg/dL] & $5.47 \pm 1.34$ & $5.038 \pm 1.42$ & 0.213 \\
\hline hsCRP & $1.4(0.5,3.22)$ & $0.6(0.30,2.9)$ & 0.319 \\
\hline Treatment with statins [\%] & - & 68 & - \\
\hline Anti-hypertensive drugs [\%] & - & 72 & - \\
\hline Metformin use [\%] & - & 70 & - \\
\hline Sulphonylureas use [\%] & - & 30 & - \\
\hline
\end{tabular}

$\mathrm{BMI}$ - body mass index; Chol — cholesterol; DBP — diastolic blood pressure; FBS — fasting blood sugar; HbA $1 \mathrm{c}$ - glycated hemoglobin; $\mathrm{HDL}$ - high density lipoprotein; HOMA2-IR - homeostatic model assessment of insulin resistance; hsCRP — high-sensitivity CRP; LDL — low density; SBP — systolic blood pressure; TG — triglyceride; WHR — waist to hip ratio; lipoprotein; P-values were calculated using student's " $\mathrm{t}$ " test and Mann-Whitney " $\mathrm{U}$ " test

\section{Statistical analysis}

All analyses were carried out by the Windows-based statistical program SPSS version 22 (SPSS Inc., Chicago, USA) and GraphPad Prism, version 6.0 (GraphPad Software Inc., USA). All variables were checked for the normality of distribution with Kolmogorov Simonov test, and variables that scored under 0.05 in normality test, undergone logarithmic transformation prior to analysis. Values of variables are presented as mean \pm SD for parametric variables, and nonparametric variables are shown as the median and the $25^{\text {th }}$ to the $75^{\text {th }}$ interquartile range. Differences between the groups were assessed by use of two-tailed unpaired Student's t-test and Mann-Whitney $U$ test. The ANOVA test was used for the correction of the confounding factors (age and weight). Pearson correlation and Spearman's correlation analysis was performed to determine the relationship of variables with the expression of target genes, and also partial correlation was conducted to adjust for confounders. P-value $<0.05$ was considered statistically significant.

\section{Results}

A total of 31 non-diabetic individuals and 32 diabetic patients were enrolled in this study. The clinical and biochemical characteristics of the study population are shown in Table 2. There is no meaningful difference between BMI and waist to hip ratio (WHR) variables of the study groups; however, their mean age varies significantly $(p<0.0001)$. On the one hand, fasting blood glucose $(p<0.0001), \mathrm{HbA}_{1 c}(p<0.0001)$, serum triglycerides $(P=0.024)$, insulin $(P=0.003)$, and HOMA2-IR ( $P=0.016)$ values were significantly higher in diabetic patients compared with non-diabetic subjects. On the other hand, total cholesterol ( $p<0.0001)$ and LDL-C ( $p<0.0001)$ were significantly lower in diabetic patients, when compared to non-diabetic subjects. Also, it is worth mentioning that we did not observe any significant differences in mean values of HDL-C, urea, creatinine, and uric acid between the study groups.

Transcriptional analysis of oxidative stress markers uncovered that the gene expression of Keap-1 


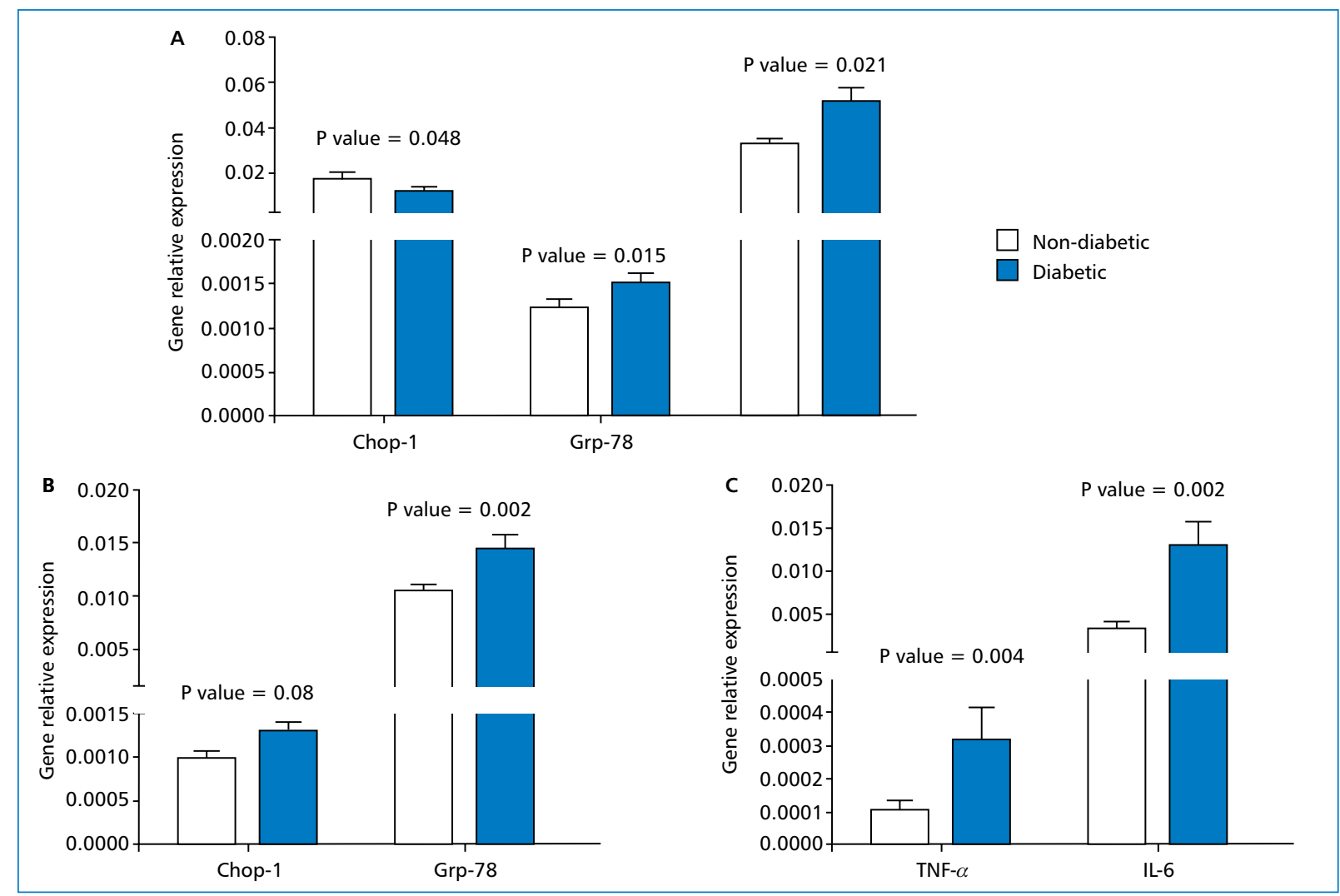

Figure 1. Transcription levels of (A) oxidative stress-associated genes, (B) ER stress-related genes, and (C) inflammatory genes after adjustment for age, BMI and drug consumption. Data are presented as mean \pm SEM. The statistical significance of differences was calculated employing the software GraphPad Prism, version 6.0 (GraphPad Software Inc., USA), using one-way ANOVA. Results were considered significantly different when P-value $<0.05$

and $\mathrm{p} 22^{\text {phox }}$ is significantly increased in the PBMCs of diabetic patients compared with the control group. Conversely, the data indicated that the gene expression of Nrf2 is significantly decreased in diabetic patients in comparison to non-diabetic subjects (Figure 1A). The relative mRNA expression of both ER stress markers (Grp-78 and Chop-1) was upraised in PBMCs of patients with diabetes compared to control subjects (Figure 1B). Also, genes of pro-inflammatory cytokines (IL-6 and TNF- $\alpha$ ) were higher expressed in diabetic PBMCs compared to non-diabetic cells (Figure 1C).

Analysis of oxidant markers in serum demonstrated that MDA $(P=0.0001)$ and carbonyl content $(P=0.002)$ have elevated extendedly in diabetic patients. Also these patients had lower levels of FRAP $(P=0.007)$ and total thiol $(P=0.002)$ (Table 3$)$. These data strongly indicate that oxidative stress is more developed in the PBMCs of diabetic patients compared to the control group.

In order to investigate the connections of oxidative stress with ER stress and inflammation, we performed partial correlation analysis. Table 4 presents the data of partial correlation analysis between the relative expression of genes and oxidative stress markers. Adjustments were performed for age, BMI and drug consumption. The gene expression of Nrf2 was negatively correlated with MDA and carbonyl content. Conversely, mRNA levels of Nrf2 was positively associated with FRAP. Furthermore, the genes expression were found to be associated with each other significantly. Importantly, results showed a strong negative correlation of Nrf2 with oxidative stress related genes (Keap1 and p22 ${ }^{\text {phox }}$ ) and IL-6. Interestingly, there was a positive correlation between gene expression of Nrf2 and ER stress-related genes. Gene expression of oxidative stress related genes (Keap1 and p22 ${ }^{\text {phox }}$ ) were positively correlated with inflammatory genes, ER stress related genes and MDA.

Moreover, mRNA levels of ER stress related genes were evaluated in association with oxidative stress associated markers and inflammatory genes. The expression levels of Chop1 and Grp78 had correlation with MDA, IL-6 and TNF- $\alpha$. Furthermore, pro-inflammatory genes, in a same fashion, showed association with MDA and carbonyl content.

We also evaluated the correlation of clinical and biochemical parameters with selected gene expressions. As shown in Table 5, while Nrf2 had negative significant correlation with age, FBS and $\mathrm{HbA}_{1 \mathrm{c}^{\prime}}$ Keap1 showed 
Table 3. Oxidative stress markers of the study groups

\begin{tabular}{lccc}
\hline Parameter & Non-diabetic subjects & Diabetic patients & P-value \\
\hline MDA $[\mu \mathrm{mol} / \mathrm{l}]$ & $2.30 \pm 0.39$ & $3.35 \pm 1.02$ & 0.0001 \\
FRAP $[\mu \mathrm{mol} / \mathrm{l}]$ & $882.60 \pm 146.73$ & $756.65 \pm 134.81$ & 0.007 \\
Carbonyl protein $[\mathrm{nmoL} / \mathrm{mg}$ protein] & $7.83 \pm 1.10$ & $9.42 \pm 1.83$ & 0.002 \\
Total thiol $[\mu \mathrm{mol} / \mathrm{L}]$ & $211.80 \pm 61.05$ & $155.37 \pm 51.28$ & 0.002 \\
\hline
\end{tabular}

FRAP — ferric reducing ability of plasma; MDA — malondialdehyde; LDL — low density. P-values were calculated using student's " $t$ " test and Mann-Whitney "U" test

Table 4. Partial correlation of selected genes with oxidative stress markers in whole population

\begin{tabular}{|c|c|c|c|c|c|c|c|c|c|c|}
\hline & Nrf2 & Keap1 & $P 22^{\text {phox }}$ & Grp78 & Chop1 & TNF- $\alpha$ & IL-6 & MDA & FRAP & Total thiol \\
\hline Keap1 & $-0.291^{*}$ & - & - & - & - & - & - & - & - & - \\
\hline $\mathrm{p} 22^{\text {phox }}$ & $-0.408^{*}$ & $0.376^{*}$ & - & - & - & - & - & - & - & - \\
\hline Grp78 & $0.315^{*}$ & $0.327^{*}$ & $0.404^{*}$ & - & - & - & - & - & - & - \\
\hline Chop1 & $0.378 *$ & $0.378 *$ & $0.367^{*}$ & $0.579 * *$ & - & - & - & - & - & - \\
\hline TNF- $\alpha$ & 0.132 & $0.366^{*}$ & $0.423 *$ & $0.401 *$ & $0.405^{*}$ & - & - & - & - & - \\
\hline IL-6 & $-0.365^{*}$ & $0.333^{*}$ & $0.389 *$ & $0.441^{*}$ & $0.414^{*}$ & $0.454^{* *}$ & - & - & - & - \\
\hline MDA & $-0.353^{*}$ & $0.449 * *$ & $0.514^{*}$ & $0.427^{*}$ & $0.443 *$ & $0.492 *$ & $0.548^{* *}$ & - & - & - \\
\hline FRAP & $0.344^{*}$ & $-0.368^{*}$ & $-0.428^{*}$ & 0.191 & 0.014 & $-0.506 * *$ & 0.200 & $-0.397^{*}$ & - & - \\
\hline Total thiol & 0.193 & 0.072 & 0.044 & 0.011 & 0.114 & -0.078 & $-0.410 *$ & $-0.384^{*}$ & $0.359 *$ & - \\
\hline Carbonyl & $-0.337^{*}$ & 0.073 & -0.028 & $0.446^{*}$ & 0.065 & 0.104 & $0.516^{*}$ & $0.389 *$ & $-0.401 *$ & $-0.444^{*}$ \\
\hline
\end{tabular}

*P-value $<0.05 ;$ **P-value $<0.01$. P-values were calculated using student's " $t$ " test and Mann-Whitney "U" test

Table 5. Correlation of clinical and biochemical parameters with selected gene expressions

\begin{tabular}{|c|c|c|c|c|c|c|c|}
\hline Variable & Nrf2 & Keap1 & p22phox & Grp78 & Chop1 & TNF- $\alpha$ & IL-6 \\
\hline Age & $-0.417^{*}$ & -0.070 & 0.039 & 0.039 & 0.120 & 0.082 & 0.120 \\
\hline BMI & 0.048 & 0.073 & 0.020 & 0.230 & -0.046 & $0.398^{*}$ & 0.420 ** \\
\hline FBS & $-0.355^{* *}$ & $0.276^{*}$ & $0.456^{* *}$ & $0.453^{* *}$ & $0.439 * *$ & $0.347^{*}$ & $0.334^{*}$ \\
\hline Chol & $0.272^{*}$ & $-0.335^{*}$ & -0.119 & -0.031 & -0.090 & -0.069 & $-0.399^{*}$ \\
\hline TG & 0.175 & $0.265^{*}$ & 0.176 & $0.376^{*}$ & $0.322^{*}$ & $0.383^{*}$ & 0.139 \\
\hline HDL-c & 0.143 & $-0.263^{*}$ & 0.008 & $-0.386^{*}$ & $-0.360 *$ & $-0.376^{*}$ & $-0.463^{* *}$ \\
\hline LDL-C & $0.311^{*}$ & $-0.314^{*}$ & -0.179 & -0.065 & -0.182 & -0.122 & -0.330 * \\
\hline $\mathrm{HbA}_{1 \mathrm{c}}$ & $-0.301 *$ & 0.293 & $0.574^{* *}$ & $0.367^{*}$ & $0.314^{*}$ & $0.459 * *$ & $0.483^{* *}$ \\
\hline
\end{tabular}

${ }^{*}$ P-value $<0.05 ;{ }^{* *}$ P-value $<0.01$, the analysis was performed by ANCOVA test on whole population and all the analyses were adjusted for confounding variables. BMI - body mass index; Chol - cholesterol; FBS - fasting blood sugar; $\mathrm{HbA}_{1 c}$ - glycosylated haemoglobin; $\mathrm{HDL}$ - high density lipoprotein; TG — triglyceride

positive correlation with FBS. Another gene involved in oxidative stress, $\mathrm{p} 22^{\text {phox }}$ was associated with FBS and $\mathrm{HbA}_{1 \mathrm{c}}$. Concerning the ER stress related genes, Chop1 and Grp78, both had positive correlation with FBS, $\mathrm{HbA}_{1 \mathrm{c}}$ and TG. In addition, TNF- $\alpha$ was associated with BMI, FBS and $\mathrm{HbA}_{1 \mathrm{c}}$.

\section{Discussion}

Now there are convincing shreds of evidence that T2DM is affecting human beings' life drastically, therefore it seems that developing the best ways of management of the disease is substantial. Obesity, hypertension, aging, dyslipidemia, hyperglycemia, cigarette smoking, sedentary lifestyle, and family history of diabetes are the most known leading factors in the development of T2DM. Sustained hyperglycemia is associated with oxidative stress, inflammation, ER stress. It is required to consider the effects of oxidative stress, inflammation, ER stress, and many other factors in the pathogenesis of T2DM. However, most of these 
factors are well-examined and explained in the previous studies, but the exploring roles of mentioned factors in clinical settings are in great demand.

Our data revealed that many biological and clinical indexes are changed in diabetic patients. We found that the levels of serum cholesterol and LDL-C are lower in diabetic patients in comparison with the control group. We think that it might be associated with the consumption of lipid-lowering drugs in the diabetic group. Oxidative stress is one of the leading factors in the pathogenesis of T2DM. In this study, we assessed a series of oxidative stress markers in the serum of the subjects. Similar to previous reports [24-32], we observed rise in protein oxidation (protein carbonyls), lipid peroxidation (MDA), diminution of total thiol content, and decrease of total antioxidant capacity (FRAP) in diabetic patients compared to the healthy subjects. In this regard, we also analyzed the gene expression levels of oxidative stress related genes in the PBMCs of both groups. In accordance with findings of previous studies, transcriptional analysis of oxidative stress-related genes revealed that the gene expression of Nrf2 is reduced in the diabetes group, while mRNA levels of both Keap1 and p22phox were elevated in the diabetic group when compared to the healthy subjects $[27,33]$. Similar to our findings, in the study of Rabbani et al. [34] the protein levels of Nrf2 and Keap1 were decreased and increased, respectively. Also, it has been shown that Keap1 knockdown in diabetic bone marrow-derived cells resulted in Nrf2 upregulation. Concurrently, the downregulation of Nrf2 leads to ROS accumulation. In addition, the authors established the $\mathrm{Nrf2/Keap1}$ as a cytoprotective pathway in the cells and the downregulation of Nrf2 leads to ROS accumulation. Furthermore, in agreement with the previous reports on important role of hyperglycemia in inducing oxidative stress [35-37], we were able to demonstrate an association between Nrf2, Keap1 and p22phox expression levels with the glycemic indexes (FBS and HbA1c). Taken together, these findings suggest an impairment of the antioxidant defenses system in PBMCs of the diabetic patients.

The main goal of our study was to investigate the correlations of oxidative stress, ER stress and inflammation as these are the three main factors in the development of insulin resistance and $B$ cell dysfunction in diabetic patients. Our data revealed that there is a positive correlation between the expression of Nrf2, Grp78, and Chop1 genes. In eukaryotic cells, folding and trafficking of almost all membrane proteins and most secreted proteins are executed in the endoplasmic reticulum. Moreover, ER is involved in the energy metabolism, apoptosis, homeostasis of intracellular $\mathrm{Ca}_{2}{ }^{+}$ and reduction-oxidation (redox) balance [38]. When the ER is under stress, ROS can be produced in the ER as a byproduct of oxidative protein folding. This incident can contribute to mitochondrial ROS production and cause oxidative stress. Recent insights have shown that ER and mitochondria are connected to each other by mitochondria-associated ER membranes (MAMs) [39]. Therefore, the oxidative stress and ER stress are coexisted most of the time and induce each other. As we mentioned earlier, Nrf2 is a transcription factor that participates in cell survival mechanisms by induction of antioxidants genes such as superoxide dismutases (SODs), glutathione peroxidases, peroxiredoxins, and catalase. Collectively, in a stressed cell, Nrf2 pathway functions as a system to rescue cells from death by suppressing both ER stress and oxidative stress. Consistent with this idea, we found that there is a positive relationship between oxidative stress and ER stress markers in the mRNA level in diabetic patients, indicating the interconnectivity of these parameters.

It has been shown that PBMCs are representative cells for studying inflammatory pathways, oxidative stress, dyslipidemia, and glucose metabolism[40]. Therefore, in this study, we used PBMCs as a model of inflammatory cells to determine the possible correlations of inflammatory cytokines and oxidative stress markers. We observed a negative correlation between Nrf2 and IL- 6 gene expressions. In a study by Thimmulappa et al. [41] LPS stimulation resulted in ROS production as well as a rise in the levels of TNF- $\alpha$ and IL-6 in peritoneal neutrophils of mice. However, the authors have declared that these factors are more elevated in nrf2 -/- cells compared to nrf2 +/+ cells, showing the protective role of Nrf2 against inflammation. Moreover, the authors have stated that the effects of pro-inflammatory cytokines on nrf2 -/- neutrophils are mediated through ROS signaling [41]. In the present study unlike for IL-6, we did not observe any significant correlation between Nrf2 and TNF- $\alpha$. Considering former studies, there are contradictory findings regarding the correlation between Nrf2 and TNF- $\alpha$. In a study by Gobinath Shanmugam et al. [42] it was shown bimodal effects of TNF- $\alpha$ on Nrf2 in $\mathrm{HL}-1$ cardiomyocytes. Treatment of cells with $2-5 \mathrm{ng} / \mathrm{mL}$ of TNF- $\alpha$ increased importation of Nrf2 into the nucleus. Conversely, higher doses of TNF- $\alpha$ (>10-50 ng/ml) repressed gene expression of Nrf2. The authors concluded that the oxidative response of Nrf2 has two phases and the second phase is regulated by the other factors than Nrf2[42]. In Nrf2 (-/-) mice the gene expression of TNF- $\alpha$ was increased significantly, showing the important role of Nrf2 in controlling inflammation [43]. It is of note that PBMCs in the present study were in 


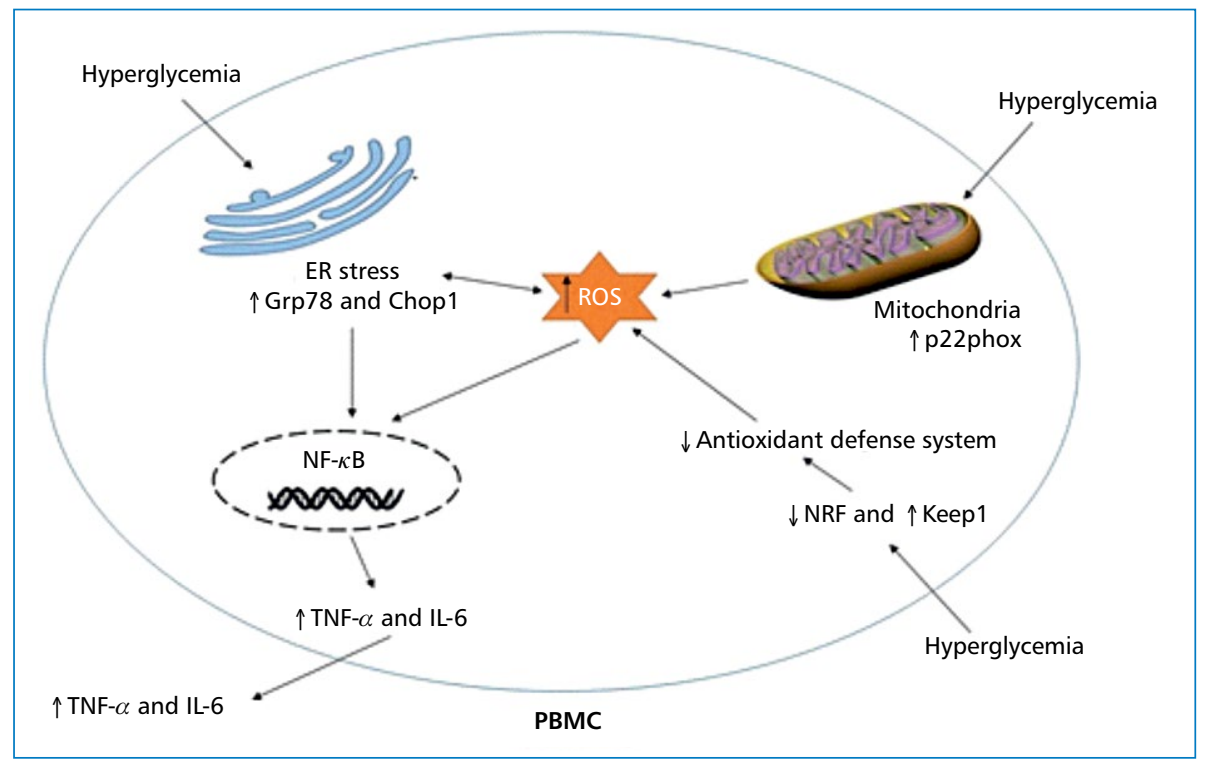

Figure 2. Schematic representation of the interconnections of the ER-stress, oxidative stress and inflammation in PBMCs. According to the figure, hyperglycemia activates several signaling pathways including ER-stress (increased Grp78 and Chop1), oxidative stress (increased p22phos, decreased Nrf2) and inflammation (increased TNF- $\alpha$ and IL-6). In addition, activation of each pathway is correlated with the activation of the two other pathways leading to induction of inflammatory responses in PBMCs cells

the basal, but not stimulated state and this could be a reason for not observing a significant association between Nrf2 and TNF- $\alpha$.

In summary, hyperglycemia activates several signaling pathways including ER-stress (increased Grp78 and Chop1), oxidative stress (increased p22phos, decreased Nrf2) and inflammation (increased TNF- $\alpha$ and IL-6). In addition, activation of each pathway is correlated with the activation of the two other pathways leading to induction of inflammatory responses in PBMCs cells. The interconnections of the ER-stress, oxidative stress and inflammation in PBMCs is shown in Figure 2.

\section{Acknowledgements}

This work was supported by a financial grant by deputy of research (96-03-30-35150) from Tehran University of Medical Sciences.

\section{Conflict of interest}

The authors declare that they have no competing interests.

\section{REFERENCES}

1. Guariguata L, Whiting DR, Hambleton I, et al. Global estimates of diabetes prevalence for 2013 and projections for 2035. Diabetes Res Clin Pract. 2014; 103(2): 137-149, doi: 10.1016/j. diabres.2013.11.002, indexed in Pubmed: 24630390.

2. Cerf ME. Beta cell dysfunction and insulin resistance. Front Endocrinol (Lausanne). 2013; 4: 37, doi: 10.3389/fendo.2013.00037, indexed in Pubmed: 23542897.
3. Tangvarasittichai $\mathrm{S}$. Oxidative stress, insulin resistance, dyslipidemia and type 2 diabetes mellitus. World J Diabetes. 2015; 6(3): 456480, doi: 10.4239/wjd.v6.i3.456, indexed in Pubmed: 25897356.

4. Yki-Järvinen $\mathrm{H}$. Pathophysiology of type 2 diabetes mellitus. Oxford Textbook of Endocrinology and Diabetes. 2011: 1740-1748, doi: 10.1093/med/9780199235292.003.1336.

5. Emamgholipour S, Ebrahimi R, Bahiraee A, et al. Acetylation and insulin resistance: a focus on metabolic and mitogenic cascades of insulin signaling. Critical Reviews in Clinical Laboratory Sciences. 2020; 57(3): 196-214, doi: 10.1080/10408363.2019.1699498.

6. Styskal J, Van Remmen H, Richardson A, et al. Oxidative stress and diabetes: what can we learn about insulin resistance from antioxidant mutant mouse models? Free Radic Biol Med. 2012; 52(1): 46-58, doi: 10.1016/j.freeradbiomed.2011.10.441, indexed in Pubmed: 22056908.

7. Wang X, Hai CX. ROS acts as a double-edged sword in the pathogenesis of type 2 diabetes mellitus: is Nrf2 a potential target for the treatment? Mini Rev Med Chem. 2011; 11(12): 1082-1092, doi: 10.2174/138955711797247761, indexed in Pubmed: 21861804.

8. Halliwell $B$. The wanderings of a free radical. Free Radic Biol Med. 2009; 46(5): 531-542, doi: 10.1016/j.freeradbiomed.2008.11.008, indexed in Pubmed: 19111608.

9. Kensler TW, Wakabayashi N, Biswal S. Cell survival responses to environmental stresses via the Keap1-Nrf2-ARE pathway. Annu Rev Pharmacol Toxicol. 2007; 47: 89-116, doi: 10.1146/annurev. pharmtox.46.120604.141046, indexed in Pubmed: 16968214.

10. Itoh K, Chiba T, Takahashi S, et al. An Nrf2/small Maf heterodimer mediates the induction of phase II detoxifying enzyme genes through antioxidant response elements. Biochem Biophys Res Commun. 1997; 236(2): 313-322, doi: 10.1006/bbrc.1997.6943, indexed in Pubmed: 9240432.

11. Bhakkiyalakshmi $E$, Sireesh $D$, Rajaguru $P$, et al. The emerging role of redox-sensitive Nrf2-Keap1 pathway in diabetes. Pharmacol Res. 2015; 91: 104-114, doi: 10.1016/j.phrs.2014.10.004, indexed in Pubmed: 25447793.

12. Motohashi $H$, Yamamoto M. Nrf2-Keap1 defines a physiologically important stress response mechanism. Trends Mol Med. 2004; 
10(11): 549-557, doi: 10.1016/j.molmed.2004.09.003, indexed in Pubmed: 15519281.

13. Eizirik DL, Cardozo AK, Cnop M. The role for endoplasmic reticulum stress in diabetes mellitus. Endocr Rev. 2008; 29(1): 42-61, doi: 10.1210/er.2007-0015, indexed in Pubmed: 18048764.

14. Bertolotti A, Zhang $Y$, Hendershot $L M$, et al. Dynamic interaction of $\mathrm{BiP}$ and $\mathrm{ER}$ stress transducers in the unfolded-protein response. Nat Cell Biol. 2000; 2(6): 326-332, doi: 10.1038/35014014, indexed in Pubmed: 10854322.

15. Mozzini $C$, et al. Endoplasmic reticulum stress, NRF2 signalling and cardiovascular diseases in a nutshell. Current atherosclerosis reports, 2017. Current Atherosclerosis Reports. 2017; 19(8): 33.

16. Lenin R, Sankaramoorthy A, Mohan V, et al. Altered immunometabolism at the interface of increased endoplasmic reticulum (ER) stress in patients with type 2 diabetes. J Leukoc Biol. 2015; 98(4): 615-622, doi: 10.1189/jlb.3A1214-609R, indexed in Pubmed: 26123743.

17. Emmendoerffer $A$, Hecht $M$, Boeker $T$, et al. Role of inflammation in chemical-induced lung cancer. Toxicology Letters. 2000; 112113: 185-191, doi: 10.1016/s0378-4274(99)00285-4.

18. Lemieux I, Pascot A, Almeras N, et al. Elevated C-reactive protein: another component of the atherothrombotic profile of abdominal obesity. Arteriosclerosis, thrombosis, and vascular biology, 2001. Arterioscler Thromb Vasc Biol. 2001; 21(6): 961-967, doi: 10.1161/01.atv.21.6.961, indexed in Pubmed: 11397704

19. Ebrahimi R, Bahiraee $A$, Niazpour $F$, et al. The role of microRNAs in the regulation of insulin signaling pathway with respect to metabolic and mitogenic cascades: A review. J Cell Biochem. 2019; 120(12): 19290-19309, doi: 10.1002/jcb.29299, indexed in Pubmed: 31364207.

20. Devasagayam, T., K. Boloor, and T. Ramasarma, Methods for estimating lipid peroxidation: an analysis of merits and demerits. 2003.

21. Benzie IF, Strain JJ. The ferric reducing ability of plasma (FRAP) as a measure of "antioxidant power": the FRAP assay. Anal Biochem. 1996; 239(1): 70-76, doi: 10.1006/abio.1996.0292, indexed in Pubmed: 8660627.

22. Dalle-Donne I, Rossi R, Giustarini D, et al. Protein carbonyl groups as biomarkers of oxidative stress. Clinica Chimica Acta. 2003; 329(1-2): 23-38, doi: 10.1016/s0009-8981(03)00003-2.

23. Winther JR, Thorpe C. Quantification of thiols and disulfides. Biochim Biophys Acta. 2014; 1840(2): 838-846, doi: 10.1016/j. bbagen.2013.03.031, indexed in Pubmed: 23567800.

24. Adaikalakoteswari A, Balasubramanyam M, Rema M, et al. Differential gene expression of NADPH oxidase (p22phox) and hemoxygenase- 1 in patients with Type 2 diabetes and microangiopathy. Diabet Med. 2006; 23(6): 666-674, doi: 10.1111/j.14645491.2006.01879.x, indexed in Pubmed: 16759310.

25. Vairamon SJ, Babu M, Viswanathan V. Oxidative stress markers regulating the healing of foot ulcers in patients with type 2 diabetes. Wounds. 2009; 21(10): 273.

26. Kumawat M, Pahwa M, Gahlaut V, et al. Status of antioxidant enzymes and lipid peroxidation in type 2 diabetes mellitus with micro vascular complications. The Open Endocrinology Journal. 2009; 3(1): 12-15, doi: 10.2174/1874216500903010012.

27. Sireesh D, Dhamodharan U, Ezhilarasi K, et al. Association of NF-E2 related factor 2 (nrf2) and inflammatory cytokines in recent onset type 2 diabetes mellitus. Sci Rep. 2018; 8(1): 5126, doi: 10.1038/ s41598-018-22913-6, indexed in Pubmed: 29572460.

28. Huang $X$, Sun M, Li D, et al. Augmented NADPH oxidase activity and p22phox expression in monocytes underlie oxidative stress of patients with type 2 diabetes mellitus. Diabetes Res Clin Pract. 2011; 91(3): 371-380, doi: 10.1016/j.diabres.2010.12.026, indexed in Pubmed: 21237524.
29. Duman BS, Oztürk M, Yilmazeri S, et al. Thiols, malonaldehyde and total antioxidant status in the Turkish patients with type 2 diabetes mellitus. Tohoku J Exp Med. 2003; 201(3): 147-155, doi: 10.1620/tjem.201.147, indexed in Pubmed: 14649736.

30. Van Campenhout A, Van Campenhout $C$, Lagrou AR, et al. Impact of diabetes mellitus on the relationships between iron-, inflammatory- and oxidative stress status. Diabetes Metab Res Rev. 2006; 22(6): 444-454, doi: 10.1002/dmrr.635, indexed in Pubmed: 16506275.

31. Srivatsan R. Antioxidants and lipid peroxidation status in diabetic patients with and without complications. 2009.

32. Pasaoglu H, Sancak B, Bukan N. Lipid peroxidation and resistance to oxidation in patients with type 2 diabetes mellitus. Tohoku J Exp Med. 2004; 203(3): 211-218, doi: 10.1620/tjem.203.211, indexed in Pubmed: 15240931.

33. Zhong Q, Mishra M, Kowluru RA. Transcription factor Nrf2-mediated antioxidant defense system in the development of diabetic retinopathy. Invest Ophthalmol Vis Sci. 2013; 54(6): 3941-3948, doi: 10.1167/iovs.13-11598, indexed in Pubmed: 23633659.

34. Rabbani PS, Soares MA, Hameedi SG, et al. Dysregulation of nrf2/ keap1 redox pathway in diabetes affects multipotency of stromal cells. Diabetes. 2019; 68(1): 141-155, doi: 10.2337/db18-0232, indexed in Pubmed: 30352880.

35. Karbach $S$, Jansen $T$, Horke $S$, et al. Hyperglycemia and oxidative stress in cultured endothelial cells--a comparison of primary endothelial cells with an immortalized endothelial cell line. J Diabetes Complications. 2012; 26(3): 155-162, doi: 10.1016/j. jdiacomp.2012.03.011, indexed in Pubmed: 22521318.

36. Volpe CM, Villar-Delfino PH, Dos Anjos PM, et al. Cellular death, reactive oxygen species (ROS) and diabetic complications. Cell Death Dis. 2018; 9(2): 119, doi: 10.1038/s41419-017-0135-z, indexed in Pubmed: 29371661.

37. Sharma R, Buras E, Terashima $T$, et al. Hyperglycemia induces oxidative stress and impairs axonal transport rates in mice. PLoS ONE. 2010; 5(10): e13463, doi: 10.1371/journal. pone.0013463.

38. Cao SS, Kaufman RJ. Endoplasmic reticulum stress and oxidative stress in cell fate decision and human disease. Antioxid Redox Signal. 2014; 21(3): 396-413, doi: 10.1089/ars.2014.5851, indexed in Pubmed: 24702237.

39. Bravo R, Gutierrez T, Paredes F, et al. Endoplasmic reticulum: ER stress regulates mitochondrial bioenergetics. The International Journal of Biochemistry \& Cell Biology. 2012; 44(1): 16-20, doi: 10.1016/j.biocel.2011.10.012.

40. Visvikis-Siest S, Marteau JB, Samara A, et al. Peripheral blood mononuclear cells (PBMCs): a possible model for studying cardiovascular biology systems. Clin Chem Lab Med. 2007; 45(9): 1154-1168, doi: 10.1515/CCLM.2007.255, indexed in Pubmed: 17663631.

41. Thimmulappa RK, Scollick C, Traore K, et al. Nrf2-dependent protection from LPS induced inflammatory response and mortality by CDDO-Imidazolide. Biochem Biophys Res Commun. 2006; 351(4): 883-889, doi: 10.1016/j.bbrc.2006.10.102, indexed in Pubmed: 17097057.

42. Shanmugam G, Narasimhan M, Sakthivel R, et al. A biphasic effect of TNF- $\alpha$ in regulation of the Keap1/Nrf2 pathway in cardiomyocytes. Redox Biol. 2016; 9: 77-89, doi: 10.1016/j. redox.2016.06.004, indexed in Pubmed: 27423013.

43. Mao L, Wang H, Qiao L, et al. Disruption of Nrf2 enhances the upregulation of nuclear factor-kappaB activity, tumor necrosis factor- $\alpha$, and matrix metalloproteinase- 9 after spinal cord injury in mice. Mediators Inflamm. 2010; 2010: 238321, doi: 10.1155/2010/238321, indexed in Pubmed: 20862369. 